\title{
Adherence to Lifestyle Modification among Hypertensive Clients: A Descriptive Cross-Sectional Study
}

\author{
Yaa Obirikorang1, Christian Obirikorang2, Emmanuel Acheampong1, Enoch Odame Anto2,3, \\ Beatrice Amoah"2, Eva Fosu', Joseph A. Eshiman Amehere', Emmanuella Nsenbah Batu², \\ Peter Kojo Brenya2 ${ }^{2}$, Bright Amankwaa2*, Evans Asamoah Adu4, Adjei Gyimah Akwasi5, \\ Roberta Yaa Asiwu6
}

\author{
${ }^{1}$ Department of Nursing, Faculty of Health Sciences, Garden City University College (GCUC), Kumasi, Ghana \\ ${ }^{2}$ Department of Molecular Medicine, School of Medical Science, Kwame Nkrumah University of Science and Technology \\ (KNUST), Kumasi, Ghana \\ ${ }^{3}$ School of Medical and Health Science, Edith Cowan University, Joondalup, Australia \\ ${ }^{4}$ Department of Medical Laboratory Technology, Faculty of Allied Health Sciences, KNUST, Kumasi, Ghana \\ ${ }^{5}$ Department of Community Health, School of Medical Sciences, KNUST, Kumasi, Ghana \\ ${ }^{6}$ Department of Physiology, School of Medical Sciences, KNUST, Kumasi, Ghana \\ Email: ^brytespiro@gamil.com
}

How to cite this paper: Obirikorang, Y., Obirikorang, C., Acheampong, E., Anto, E.O., Amoah, B., Fosu, E., Amehere, J.A.E., Batu, E.N., Brenya, P.K., Amankwaa, B., Adu, E.A., Akwasi, A.G. and Asiwu, R.Y. (2018) Adherence to Lifestyle Modification among Hypertensive Clients: A Descriptive Cross-Sectional Study. Open Access Library Journal, 5: e4375.

https://doi.org/10.4236/oalib.1104375

Received: December 20, 2017

Accepted: February 24, 2018

Published: February 27, 2018

Copyright $\odot 2018$ by authors and Open Access Library Inc.

This work is licensed under the Creative Commons Attribution International License (CC BY 4.0).

http://creativecommons.org/licenses/by/4.0/

(c) (i) Open Access

\begin{abstract}
Background: Adoption of a life style modification is of critical importance for preventing and managing hypertension. This study determined the adherence to lifestyle modification among hypertensive clients at Juaso district hospital. Methodology: This was a descriptive cross-sectional study, conducted among hypertensive clients at Juaso district hospital, Kumasi, in the Ashanti Region of Ghana. A reviewed-structured questionnaire was used to collect data from the respondents. A total of 300 respondents were conveniently sampled for the study. Clients diagnosed of hypertension and who regularly met appointment dates at the Out Patient Department (OPD) for at least six months duration were included in this study. Statistical analysis was done using SPSS and p-value less than 0.05 was considered statistically significant. Results: The mean age $(\mathrm{SD})$ of the participants was 63.6 years $( \pm 11.6)$ and median duration of having hypertension was 4 years. Out of the 300 participants, $72.0 \%$ of the participants were adherent to life style modification. The level of education $(\mathrm{p}<0.0001)$, marital status $(\mathrm{p}<0.0001)$ and duration of disease $(\mathrm{p}<0.0001)$ statistically significant influenced the general rate of adherence. Participants who had secondary education [OR $=0.04(0.005-3.1), \mathrm{p} \leq 0.0001)]$, tertiary education $[\mathrm{OR}=0.8(0.01-6.3), \mathrm{p}=0.003)]$, have had hypertension for a duration of $5-10$ years $[\mathrm{OR}=2.9(1.5-5.8), \mathrm{p}=0.002)]$ and married $[\mathrm{OR}=2.3$
\end{abstract}


(1.1 - 4.9), $\mathrm{p}=0.034)]$ were significantly associated with high rate of adherence to lifestyle modification. Participants who reported of being educated on the effect of smoking and alcohol consumption [OR $=2.2(0.8-5.7), \mathrm{p} \leq$ $0.0001)]$ and exercise $[\mathrm{OR}=58.9(7.7-449.9), \mathrm{p} \leq 0.0001)]$ were significantly associated with high rate of adherence to lifestyle modification. Conclusion: The study showed that, the rate of adherence to lifestyle modification among hypertensive patients was high. Socio-demographic factors such as level of education, marital status and duration of disease significantly influenced the general rate of adherence.

\section{Subject Areas}

Internal Medicine

\section{Keywords}

Adherence, Lifestyle Modification, Hypertension

\section{Introduction}

Hypertension (HPN) is known as high or raised blood pressure, which is a global public health issue [1] [2]. It contributes to the burden of heart disease, stroke and kidney failure and premature mortality and disability. The global burden of Hypertension is rapidly increasing [3]. In traditional African societies, hypertension, once rare, is rapidly becoming a major public health burden [4]. In Sub-Saharan Africa, hypertension has emerged as a major public health concern in recent years [4] due to modernization trends, characterized by a sedentary style of life and consumption of a diet rich in refined carbohydrates and animal fat. In April 2007, Ghana health service news release identified hypertension as the number one killer in Ghana. The prevalence of hypertension has been on the increase in Ghana, with a prevalence of $28.3 \%$, age-standardized prevalence, to the new standard world population was $28.4 \%$ in Accra [5]. In patients with hypertension, life style modification can serve as initial treatment before the start of drug therapy and as an adjunct to medication-controlled blood pressure (BP), these therapies can facilitate drug step-down and drug withdrawal in highly motivated individuals who achieve and sustain lifestyle changes [6] [7].

Adoption of a life style modification is of critical importance for preventing and managing hypertension. It does not only reduce blood pressure but can delay the incidence of hypertension, enhance antihypertensive drug efficacy, and decrease cardiovascular risk irrespective of changes in blood pressure readings [8]. The prevalence of adult hypertension has been found to be persistently high in both urban and rural areas ranging from 19 to 48 percent [9]. The awareness, treatment experience, and effective control of hypertension were also found to be low with treatment levels ranging from 6.9 to 52.5 percent while control levels range from 1.7 to 12.7 percent [9] [10]. Hypertension has been found to be a significant cause of renal and heart failure in Ghana and has been one of the root 
causes of higher levels of cardiovascular diseases in Africa [11].

The management of Juaso District Hospital (JDH) desired a workable action plan towards revamping of Hypertension-Diabetes Clinic of the hospital in October, 2014. Among the objectives of revamping the Hypertension-Diabetes clinic of the hospital was health education for clients; this was to ensure that clients have informed knowledge on measures to prevent and control HPN/Diabetes. Anecdote indicates that, most clients who come for their routine monthly check-up have a blood pressure record of above $150 / 90 \mathrm{mmHg}$ even though clients claim to take their drugs as prescribed and so this gives us reasons to question their lifestyle. This leads to the number of increased admissions and readmissions of clients to avoid complications. There has not been many published works on lifestyle modification in Ghana. It is to this view that, the determination of adherence to lifestyle modifications among hypertensive clients at Juaso District is imminent. Though various studies on HPN have been conducted concerning knowledge, risk factors and/ or medication regimens in the urban centres however, little studies have been carried out on life style modification among hypertensives especially in rural Ghanaian settings. There is the need to develop appropriate strategies such as good healthcare deliveries and policies, and education aimed at reducing adverse consequences of HPN. This current study therefore sought to determine adherence to lifestyle modification of individuals living with hypertension in Juaso District of Ghana.

\section{Materials and Methods}

\subsection{Study Design/Setting}

This was a descriptive cross-sectional study conducted at JDH, located in Juaso the district capital of Asante Akim South in the Ashanti Region of Ghana. This district covers a total surface area of about 1153.3 square that form about five percent (5\%) of the total area of the Ashanti Region, and 0.5 percent of the total area of the country (Annual Performance Report, 2012). The 70-bed capacity hospital provides out-patient and in-patient services, with the vision to provide quality and universal health care delivery in the Asante Akim South district to facilitate personal and national development.

\subsection{Study Population and Subject Recruitment}

The targeted population was hypertensive patients (with blood pressure 140/90 $\mathrm{mmHg}$ ) who were on antihypertensive therapy and attending the hypertensive clinic. A simple random sampling technique was used to recruit hypertensive clients who received care in the year 2016. Averages of about 95 hypertensive clients were seen in a week and appointed for review in a month (Records JDH, 2016). Data was collected within one month with a minimum of 75 respondents contacted every week.

\subsection{Sample Size Justification}

An estimated total of 345 hypertensives were recruited from the study from a pop- 
ulation of 11,937 using response rate of $30.0 \%$, confidence level of $95 \%$ (z-score 1.96) and margin of error of 5\%. Using the Cochrane's formula [12], the minimum size required was 322 , however to accommodate a non-response rate of $10.0 \%$ and strongest statistical power and effect size, the samples were projected to 345 participants.

\subsection{Inclusion and Exclusion Criteria}

Clients diagnosed of HPN and who regularly met appointment dates at the OPD for at least six months duration were included. Undiagnosed hypertensives, pre-eclampsia and clients diagnosed of HPN for less than six months were excluded. Again, hypertensives with other comorbidities such as HIV and diabetes were excluded.

\subsection{Data Collection Tool}

A well-reviewed and structured questionnaire which consisted of two sections was used to collect data. The questions were piloted using a one-on-one interview by the study researchers who have been trained in data collection methods. Reliability coefficients ranging from 0.00 to 1.00 , with higher coefficients indicating higher levels of reliability was used to determine the validity and the reliability of the questionnaire. The reliability coefficients for all the questions were 0.923 . Changes were made to modify the questionnaire after the pilot study and the entire questionnaire was available in English. The first section covered the demographic data of the study participants which includes age, gender, educational level, marital status, occupation status duration of been diagnosed of hypertension etc. The second section constituted questions pertaining to adherence to life style modification techniques which includes dietary changes, social changes and physical activity. It was also made to retain confidentiality of respondents; copies of the instruction were administered to the respondent by the researcher. Instructions pertaining to the filling of the questionnaire were thoroughly explained to the respondents and the researcher supervised the filling of the questionnaire after which the instrument was collected from the respondents.

\subsection{Ethical Consideration}

Approval for this study was obtained from Human Research, Publication and Ethics of the School of Medical Sciences (SMS), Kwame Nkrumah University of Science and Technology (KNUST) and Juaso Hospital Administration. Participation was voluntary and written informed consent was obtained from each participant. Confidentiality was maintained and topmost priority was given to the rights and concerns of the respondents. Purpose of the study was made known to the respondents and also made aware that partaking in the study was strictly voluntary.

\section{Data Analysis}

Data analysis was performed using SPSS (Statistical Package for Social Sciences) 
version 22. There were 15 items-related to adherence rate to lifestyle modification. The 15 item measuring the adherence rate were added up to get sum index with a distribution from 7 - 15 with mean $12.2(\mathrm{SD}=1.6)$, the median split was used 12.0 which was dichotomized into two groups $1=$ high rate of adherence, $0=$ low adherence rate to lifestyle modification. The results were expressed as mean values $\pm \mathrm{SD}$. For non-parametrical distributions, the chi square test was used. . Binary logistic regression was used to assess relationship between independent variables with outcome variables. A p-value of $<0.05$ was considered significant.

\section{Results}

The study included 300 hypertensive patients for a response rate of $86.9 \%$. The mean age (SD) of the participants was 63.6 years $( \pm 11.6)$ and median duration of having hypertension was 4 years. Higher proportions (34.0\%) of the participants were within the age range of $61-70$ years, and $62.0 \%$ were males. Most of the participants were self-employed $(43.7 \%, 131 / 300)$, married $(62.3 \%, 187 / 300)$ and have had their education to the senior high school level (38.0\%, 114/300). Majority of the participants reported to attend their routine monthly appointment all the time $(81.3 \%, 244 / 300)$ and have had HPN in a range of less than 5 years $(52.3 \%, 157 / 300)$ (Table 1$)$.

Figure 1 shows the prevalence of adherence to lifestyle modifications. Out of the 300 participants $216(72.0 \%)$ of the participants were adherent to lifestyle modification whiles $28.0 \%$ were non adherent.

The majority of the participants didn't take in eggs (76.3\%), fried food $(68.0 \%)$ poultry $(74.0 \%)$, alcohol $(84.3 \%)$ and do not smoke too $(98.0 \%)$ respectively in a week. Most of them take in cooked salt greater than 7 times per week (68.3\%); however higher proportion did not take in added salted (92.7\%). The majority of the participants also ate fish (54.0\%), fruits (37.0\%) and vegetables (47.3\%) 4 to 7 times per week (Table 2).

Higher proportion of the participants knew smoking and alcohol consumption can affect blood pressure (94.0\%), have been educated by health personnel on the effect of smoking and alcohol (94.0\%) and exercise (94.0\%) in relation to their condition. The majority of the participants rate their overall physical activity as level 3 (regular physical activity) (40.7\%) and their daily work activity involved sitting (47.0\%). Most of the participants spent 0 - 14 minutes during every exercise session (37.0\%) with brisk waking being the highest frequency represented type of exercise among study participants (Table 3).

The level of education, marital status and duration of disease statistically significant influenced the general rate of adherence $(\mathrm{p}<0.0001)$. High adherence rate was frequently represented among participants within the age group of 61 70 years $(30.6 \%$, married hypertensives (68.5\%), self-employed (43.5\%) and have had the disease for $<5$ years $(50.9 \%)$ respectively. Further logistic regression model, revealed the participants who have had hypertension for $5-10$ years [OR = $2.9(1.5-5.8), \mathrm{p}=0.002)]$ and married $[\mathrm{OR}=2.3(1.1-4.9), \mathrm{p}=0.034)]$ were 
Table 1. Socio-demographic characteristics of the study participants.

\begin{tabular}{|c|c|c|}
\hline Variables & Frequency (n) & Percentages (\%) \\
\hline Age (years) $($ Mean $\pm S D)$ & $63.6 \pm 11.6$ & \\
\hline Duration of disease (years) (Median, IQR) & $4.0(2.0-8.0)$ & \\
\hline \multicolumn{3}{|l|}{ Age groups (years) } \\
\hline $30-40$ & 15 & $5.0 \%$ \\
\hline $41-50$ & 37 & $12.3 \%$ \\
\hline $51-60$ & 50 & $16.7 \%$ \\
\hline $61-70$ & 102 & $34.0 \%$ \\
\hline $70+$ & 96 & $32.0 \%$ \\
\hline \multicolumn{3}{|l|}{ Gender } \\
\hline Male & 186 & $62.0 \%$ \\
\hline Female & 114 & $38.0 \%$ \\
\hline \multicolumn{3}{|l|}{ Marital status } \\
\hline Single & 6 & $2.0 \%$ \\
\hline Married & 187 & $62.3 \%$ \\
\hline Divorced & 62 & $20.7 \%$ \\
\hline Separated & 8 & $2.7 \%$ \\
\hline Widowed & 37 & $12.3 \%$ \\
\hline \multicolumn{3}{|l|}{ Educational level } \\
\hline Uneducated & 27 & $9.0 \%$ \\
\hline Primary & 6 & $2.0 \%$ \\
\hline JHS & 88 & $29.3 \%$ \\
\hline SHS & 114 & $38.0 \%$ \\
\hline Tertiary & 65 & $21.7 \%$ \\
\hline \multicolumn{3}{|l|}{ Duration of disease (years) } \\
\hline$<5$ & 157 & $52.3 \%$ \\
\hline $5-10$ & 97 & $32.3 \%$ \\
\hline $11-15$ & 22 & $7.3 \%$ \\
\hline$>15$ & 24 & $8.0 \%$ \\
\hline \multicolumn{3}{|l|}{ Occupational status } \\
\hline Government employee & 86 & $28.7 \%$ \\
\hline Self-employed & 131 & $43.7 \%$ \\
\hline Student & 1 & $0.3 \%$ \\
\hline Unemployed & 82 & $27.3 \%$ \\
\hline \multicolumn{3}{|l|}{ Consistency of routine monthly appoints } \\
\hline All the time & 244 & $81.3 \%$ \\
\hline Most of the time & 56 & $10.7 \%$ \\
\hline
\end{tabular}

JHS: Junior High School, SHS: Senior High School, SD = Standard Deviation, IQR = Inter Quartile Range. 
Table 2. Frequency distribution of dietary changes among study participants.

\begin{tabular}{ccccc}
\hline Variables & None (<1) & $\mathbf{1 - 3}$ & $\mathbf{4 - 7}$ & $>\mathbf{7}$ \\
\hline Eggs & $229(76.3 \%)$ & $67(22.3 \%)$ & $4(1.3 \%)$ & - \\
Fried food (fried meat, eggs) & $204(68.0 \%)$ & $92(30.6 \%)$ & $4(1.3 \%)$ & \\
Cooked salt & $21(7.0 \%)$ & $12(4.0 \%)$ & $62(20.7 \%)$ & $206(68.3 \%)$ \\
Added salt & $278(92.7 \%)$ & $2(0.7 \%)$ & $20(6.7 \%)$ & - \\
Fish & $8(2.7 \%)$ & $80(26.7 \%)$ & $162(54.0 \%)$ & $50(16.7 \%)$ \\
Beef pork or lamb & $105(35.0 \%)$ & $195(65.0 \%)$ & - & - \\
Poultry & $222(74.0 \%)$ & $60(24.7 \%)$ & $18(6.0 \%)$ & - \\
Fruits & $6(2.0 \%)$ & $182(60.7 \%)$ & $111(37.0 \%)$ & $1(0.3 \%)$ \\
Vegetables & $2(0.6 \%)$ & $138(46.0 \%)$ & $142(47.3 \%)$ & $18(6.0 \%)$ \\
Alcohol consumption & $253(84.3 \%)$ & $47(15.6 \%)$ & - & - \\
Smoking & $294(98.0 \%)$ & $6(2.0 \%)$ & - & - \\
\hline
\end{tabular}

significantly associated with high rate of adherence to lifestyle modification (Table 4).

As shown in Table 5, there was no significant association of participants knowing the effect of smoking and alcohol consumption with adherence rate $(\mathrm{p}=0.095)$. Participants who reported of being educated on the effect of smoking and alcohol consumption $[\mathrm{OR}=2.2(0.8-5.7), \mathrm{p} \leq 0.0001)]$ and exercise $[\mathrm{OR}=58.9(7.7-449.9), \mathrm{p} \leq 0.0001)]$ were significantly associated with high rate of adherence to lifestyle modification.

\section{Discussion}

This study determined adherence to lifestyle modification among hypertensive at Juaso District hospital Findings from this study showed that out of the 300 participants, $216(72.0 \%)$ were adherent to life style modification. This is higher compared to studies done in Saudi Arabia and Ethiopia which reported low adherence rates of $4.2 \%$ and $23 \%$ respectively Tibebu, et al. [13]. The discrepancies in the adherence rate between our study and the others may be attributed to methodological settings and the two year prior health education given to clients on the knowledge of prevention and control of HPN/ diabetes in the Juaso district. The mean age $(\mathrm{SD})$ of the participants was 63.6 years $( \pm 11.6)$ with high percentage within the age range of $61-70$. This finding is consistent with other studies by Elbur [14] and Okwuonu et al. [15] who reported higher prevalence of HPN among the aged. More males (62.0\%) were observed among the study participants and are consistent with S. Shrestha [16] who also reported similar trend of HPN prevalence among men.

Association between socio-demographics and adherence to lifestyle modification showed that level of education, marital status and duration of disease significantly influenced the general rate of adherence. With education, participants 
Table 3. Frequency distribution of social centered changes and physical activity.

\begin{tabular}{|c|c|c|}
\hline Variables & Frequency $(n=300)$ & Percentages (\%) \\
\hline \multicolumn{3}{|c|}{ Do you know smoking and alcohol consumption affect blood pressure } \\
\hline No & 18 & $6.0 \%$ \\
\hline Yes & 282 & $94.0 \%$ \\
\hline \multicolumn{3}{|c|}{ Being educated on the effect of smoking and alcohol consumption } \\
\hline No & 28 & $9.3 \%$ \\
\hline Yes & 272 & $90.0 \%$ \\
\hline \multicolumn{3}{|c|}{ Being educated on exercise by health personnel } \\
\hline No & 18 & $6.0 \%$ \\
\hline Yes & 282 & $94.0 \%$ \\
\hline \multicolumn{3}{|c|}{ Rating of overall physical activity } \\
\hline Level-1 little or no activity & 60 & $20.0 \%$ \\
\hline Level-2 occasional activity & 118 & $39.3 \%$ \\
\hline Level-3 regular physical activity & 122 & $40.7 \%$ \\
\hline \multicolumn{3}{|c|}{ Involvement of daily work activity } \\
\hline Sitting & 141 & $47.0 \%$ \\
\hline Standing & 25 & $8.3 \%$ \\
\hline Walking or other exercise & 133 & $44.3 \%$ \\
\hline Heavy labour & 1 & $0.3 \%$ \\
\hline \multicolumn{3}{|c|}{ During of exercise per each session } \\
\hline $0-14$ & 111 & $37.0 \%$ \\
\hline $15-29$ & 54 & $18.0 \%$ \\
\hline $30-44$ & 74 & $24.7 \%$ \\
\hline $45-59$ & 61 & $20.3 \%$ \\
\hline \multicolumn{3}{|c|}{ Type of physical exercise that you engage in } \\
\hline Brisk walking & 174 & $58.0 \%$ \\
\hline Jogging & 39 & $13.0 \%$ \\
\hline Aerobics & 21 & $7.0 \%$ \\
\hline \multicolumn{3}{|c|}{ Complications of Hypertension } \\
\hline Stroke & 248 & $82.7 \%$ \\
\hline Heart failure & 33 & $11.0 \%$ \\
\hline Erectile dysfunction & 10 & $3.3 \%$ \\
\hline Retinopathy & 9 & $3.0 \%$ \\
\hline
\end{tabular}

who had secondary and tertiary education were more likely to adhere to lifestyle modifications. This is consistent with a study by Elbur [14] in Ethiopia who reported that the level of adherence was significantly associated with higher educational status. A higher educational level helps the patients in understanding educational information about the disease. Moreover, highly educated patients have better chance to come across considerable information on the disease from different educational sources. 
Table 4. Distribution of adherence rate to lifestyle modification in relation to socio-demographic characteristics.

\begin{tabular}{|c|c|c|c|c|c|}
\hline Variables & $\begin{array}{l}\text { High } \\
\text { adherence }\end{array}$ & $\begin{array}{c}\text { Low } \\
\text { Adherence }\end{array}$ & $\begin{array}{c}\mathrm{X}^{2} \\
\mathrm{df}(\mathrm{p} \text {-value })\end{array}$ & $\begin{array}{c}\text { OR } \\
(95 \% \mathrm{CI})\end{array}$ & p-value \\
\hline Age groups (years) & & & $2.7,4(0.602)$ & & \\
\hline $30-40$ & $9(4.2 \%)$ & $6(7.1 \%)$ & & 1 & \\
\hline $41-50$ & $26(12.0 \%)$ & $11(13.1 \%)$ & & $1.6(0.5-5.5)$ & 0.525 \\
\hline $51-60$ & $37(17.1 \%)$ & $13(15.5 \%)$ & & $1.9(0.6-6.4)$ & 0.340 \\
\hline $61-70$ & $78(36.1 \%)$ & $24(28.6 \%)$ & & $2.2(0.7-6.7)$ & 0.207 \\
\hline $70+$ & $66(30.6 \%)$ & $30(35.7 \%)$ & & $1.5(0.5-4.5)$ & 0.558 \\
\hline Gender & & & 0.070 & & \\
\hline Male & $76(35.2 \%)$ & $38(45.2 \%)$ & & 1 & \\
\hline Female & $140(64.8 \%)$ & $46(54.8 \%)$ & & $1.5(0.9-2.5)$ & 0.114 \\
\hline Marital status & & & $22.6,4(<0.0001)$ & & \\
\hline Single & $6(2.8 \%)$ & $1(1.2 \%)$ & & & \\
\hline Married & $148(68.5 \%)$ & $38(45.2 \%)$ & & $2.3(1.1-4.9)$ & 0.034 \\
\hline Divorced & $32(14.8 \%)$ & $30(35.7 \%)$ & & $0.6(0.3-1.5)$ & 0.403 \\
\hline Separated & $7(3.2 \%)$ & $1(1.2 \%)$ & & $4.3(0.5-38.4)$ & 0.236 \\
\hline Widowed & $23(10.6 \%)$ & $14(16.7 \%)$ & & 1 & \\
\hline Educational level & & & $36.3,4(<0.0001)$ & & \\
\hline Uneducated & $26(12.0 \%)$ & $1(1.2 \%)$ & & 1 & \\
\hline Primary & $5(2.3 \%)$ & $1(1.2 \%)$ & & $0.2(0.01-3.6)$ & 0.335 \\
\hline JHS & $45(20.8 \%)$ & $43(51.2 \%)$ & & $0.04(0.005-3.1)$ & $<0.0001$ \\
\hline SHS & $96(44.4 \%)$ & $18(21.4 \%)$ & & $0.2(0.03-1.6)$ & 0.124 \\
\hline Tertiary & $44(20.4 \%)$ & $21(25.0 \%)$ & & $0.8(0.01-6.3)$ & 0.003 \\
\hline Occupational status & & & $2.3,3(0.505)$ & & \\
\hline Government employee & $66(30.6 \%)$ & $20(23.8 \%)$ & & $1.6(0.8-3.2)$ & 0.174 \\
\hline Self-employed & $94(43.5 \%)$ & 37 (44.0\%) & & $1.3(0.7-2.3)$ & 0.539 \\
\hline Student & $1(0.5 \%)$ & $0(0.0 \%)$ & & & \\
\hline Unemployed & $55(25.5 \%)$ & $27(32.1 \%)$ & & 1 & \\
\hline $\begin{array}{l}\text { Duration of disease } \\
\text { (years) }\end{array}$ & & & $28.3,(<0.0001)$ & & \\
\hline$<5$ & $110(50.9 \%)$ & 47 (56.0\%) & & 1 & \\
\hline $5-10$ & $85(39.4 \%)$ & $12(14.3 \%)$ & & $2.9(1.5-5.8)$ & 0.002 \\
\hline $11-15$ & $11(5.1 \%)$ & $11(13.1 \%)$ & & $0.4(0.2-1.1)$ & 0.087 \\
\hline$>15$ & $10(4.6 \%)$ & $14(16.7 \%)$ & & $0.3(0.1-0.7)$ & 0.010 \\
\hline
\end{tabular}


Table 5. Social centered changes and physical activity distribution in relation to adherence rate to life style modification.

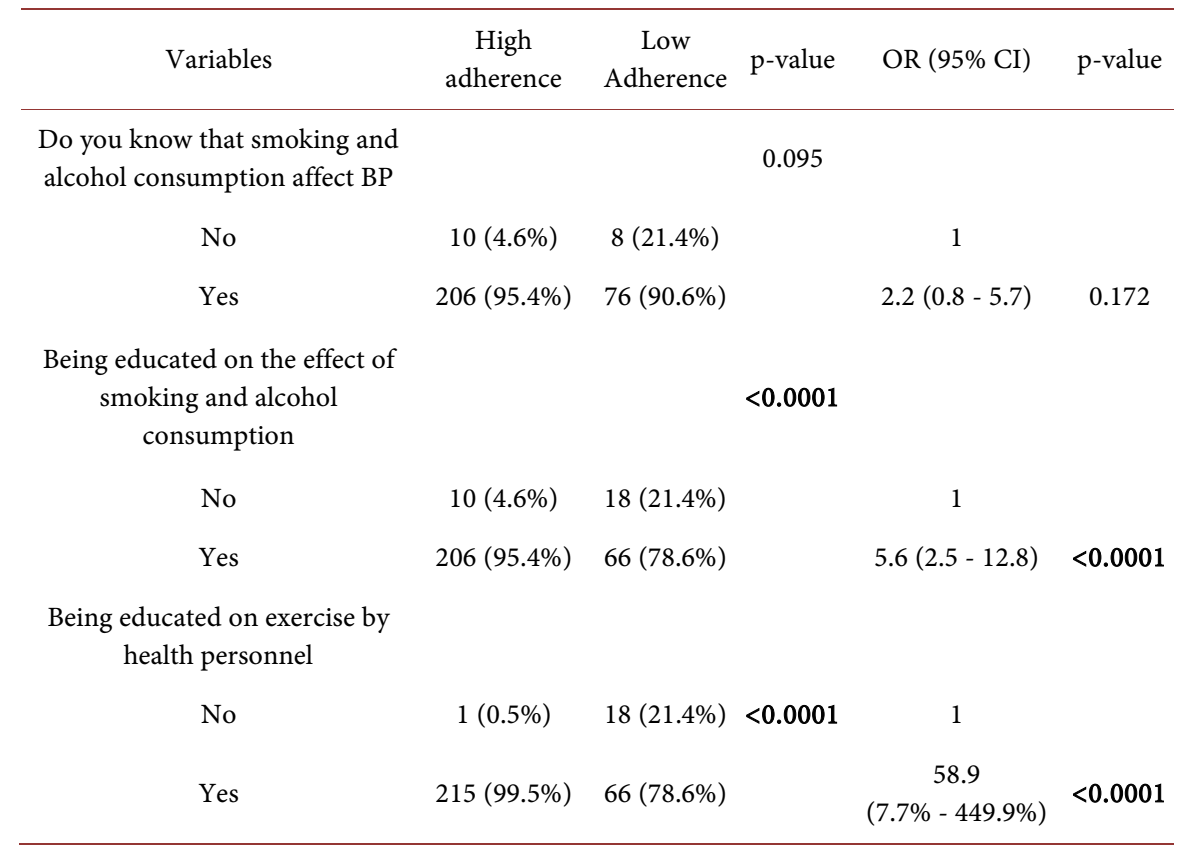

$\mathrm{OR}=$ Odds Ratio, CI-Confidence Interval, $\mathrm{X}^{2}=$ Chi-Square, $\mathrm{df}=$ Degree of freedom, $\mathrm{p}<0.05$ is statistically significant.

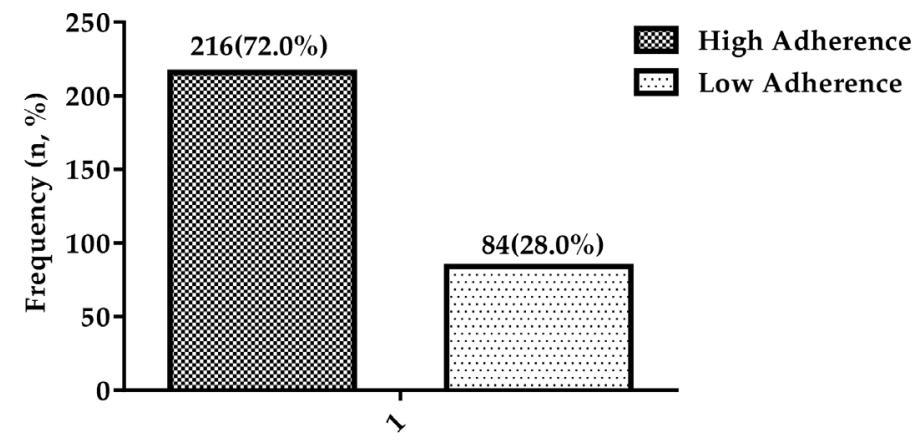

Prevalence of Adherence to lifestyle modification

Figure 1. Prevalence of adherence to lifestyle modification.

Other results showed that, participants who have had hypertension for 5 - 10 years had an increased odd of adhering to lifestyle modifications, but those with more than 15 years have reduced odds of adhering. This could be that those who have had it for more than 15 years do not see the condition as life threating anymore as compared to those with 5 - 10 years who might still follow strict lifestyle modification. Patients who have had the condition for more than 15 years might not be experiencing any symptoms even without medication. For these people, modification of lifestyle is useless; especially in patients who feel better and their health condition is improving. Among the socio demographics, participants who were married had an increased odd of adhering to lifestyle modifications. This finding is similar to the results of previous studies conducted by Lutfey and Wisher [17], Trief et al. [18], Parajuli et al. [19], and Thomas et al. 
[20]. They found that good supports from spouse, family members and friends positively predict adherence to diet and exercise recommendations. In line with our study, reason for the adherence in married couples could be the support they get from their spouse.

In this study, higher proportion of the participants knew smoking and alcohol consumption can affect blood pressure (94.0\%), and have been educated by health personnel on the effect of smoking and alcohol ((94.0\%) and exercise (94.0\%) in relation to their condition. Findings from this study showed that participants who reported of being educated on the effect of smoking and alcohol consumption, and exercise were significantly associated with high rate of adherence to lifestyle modification. This finding is supported by Yosefy et al., and Vaturi [21], who reported that, intervention program was effective on enhancing the attitude of hypertensive patients toward modifying their lifestyle and has also created a background for patients to change their practice.

Although HPN is a preventable and usually treatable disease but without treatment it leads to serious and life threatening complications such as heart, kidney and brain disorders [22]. The most common complications of HPN reported by participants in this study were stroke (82.7\%) followed by heart failure (11.0\%), erectile dysfunction (3.3\%) and retinopathy (3.0\%) respectively. According to Owusu [23] and Plange-Rhule et al. [24], HPN is an important cause of heart and renal failure in Ghana. In an examination of post-mortem records in the teaching hospital in Accra between 1994 and 1998, 11\% of deaths in adults aged 20 years or more were due to stroke, most of which were haemorrhagic and HPN a predominant factor [25]. A study by Asmar [26] also reported that HPN is the most important predictor of stroke, and its adequate treatment leads to a significant reduction in the incidence of stroke in the community. Major limitation of the study was that the rates of adherence were obtained through self-report which are subjected to recall bias. The study was not able to establish the cause of the high blood pressure in the Juaso district; as rate of adherence to lifestyle modification observed in this study was high. Moreover, this was a quantitative study where a questionnaire was solely used to collect information; therefore a qualitative study may be of value to explore into the constant high blood among hypertensive clients in the district.

\section{Conclusion}

Adherence to lifestyle modification is high among the diabetic patients at JDH after two years of educating HPN/diabetic clients on the preventive and control measures in the Juaso district. Socio-demographic factors such as level of education, marital status and duration of disease significantly influenced the general rate of adherence. It is recommended that the government and health policy makers need to assist through public educational and sensitization programs down to the community level to help effectively control HPN and its associated complications. 


\section{Acknowledgements}

The authors would like to acknowledge the management and staff of Juaso District Hospital, Department of Nursing, GCUC, Department of Molecular Medicine, for allowing us to carry this work in their departments.

\section{Conflict of Interest}

Authors declare no conflict of interest.

\section{References}

[1] Mendis, S. (2013) Hypertension: A Silent Contributor to the Global Cardiovascular Epidemic. Regional Health Forum, 2013, 1-6.

[2] WHO (2013) A Global Brief on Hypertension: Silent Killer, Global Public Health Crisis: World Health Day 2013. WHO, Geneva.

[3] Kearney, P.M., Whelton, M., Reynolds, K., Muntner, P., Whelton, P.K. and He, J. (2005) Global Burden of Hypertension: Analysis of Worldwide Data. The Lancet, 365, 217-223. https://doi.org/10.1016/S0140-6736(05)70151-3

[4] Edwards, R., Unwin, N., Mugusi, F., Whiting, D., Rashid, S., Kissima, J., Aspray, T.J. and Alberti, K.G.M. (2000) Hypertension Prevalence and Care in an Urban and Rural Area of Tanzania. Journal of Hypertension, 18, 145-152. https://doi.org/10.1097/00004872-200018020-00003

[5] Amoah, A.G., Owusu, S.K. and Adjei, S. (2002) Diabetes in Ghana: A Community Based Prevalence Study in Greater Accra. Diabetes Research and Clinical Practice, 56, 197-205. https://doi.org/10.1016/S0168-8227(01)00374-6

[6] Stamler, J., Neaton, J.D. and Wentworth, D.N. (1989) Blood Pressure (Systolic and Diastolic) and Risk of Fatal Coronary Heart Disease. Hypertension, 13, I2. https://doi.org/10.1161/01.HYP.13.5_Suppl.I2

[7] Borhani, N.O., Applegate, W.B., Cutler, J.A., Davis, B.R., Furberg, C.D., Lakatos, E., Page, L., Perry, H.M., Smith, W.M. and Probstfield, J.L. (1991) Systolic Hypertension in the Elderly Program (SHEP). Part 1: Rationale and Design. Hypertension, 17, II2. https://doi.org/10.1161/01.HYP.17.3_Suppl.II2

[8] Chobanian, A.V., Bakris, G.L., Black, H.R., Cushman, W.C., Green, L.A., Izzo Jr., J.L., Jones, D.W., Materson, B.J., Oparil, S. and Wright Jr., J.T. (2003) The Seventh Report of the Joint National Committee on Prevention, Detection, Evaluation, and Treatment of High Blood Pressure: The JNC 7 Report. JAMA, 289, 2560-2571. https://doi.org/10.1001/jama.289.19.2560

[9] Bosu, W.K. (2010) Epidemic of Hypertension in Ghana: A Systematic Review. BMC Public Health, 10, 418. https://doi.org/10.1186/1471-2458-10-418

[10] Addo, J., Agyemang, C., Smeeth, L., Aikins, A.D.G., Adusei, A. and Ogedegbe, O. (2012) A Review of Population-Based Studies on Hypertension in Ghana. Ghana Medical Journal, 46, 4-11.

[11] Cooper, R.S., Amoah, A.G. and Mensah, G.A. (2003) High Blood Pressure: The Foundation for Epidemic Cardiovascular Disease in African Populations. Ethnicity and Disease, 13, 2-48.

[12] Cochran, W.G. (1977) Sampling Techniques. 3rd Edition. John Wiley and Sons Inc., New York.

[13] Tibebu, A., Mengistu, D. and Negesa, L. (2017) Adherence to Recommended Lifestyle Modifications and Factors Associated for Hypertensive Patients Attending 
Chronic Follow-Up Units of Selected Public Hospitals in Addis Ababa, Ethiopia. Patient Preference and Adherence, 11, 323. https://doi.org/10.2147/PPA.S126382

[14] Elbur, A.I. (2015) Level of Adherence to Lifestyle Changes and Medications among Male Hypertensive Patients in Two Hospitals in Taif; Kingdom of Saudi Arabia. International Journal of Pharmacy and Pharmaceutical Sciences, 7, 168-172.

[15] Okwuonu, C., Emmanuel, C. and Ojimadu, N. (2014) Perception and Practice of Lifestyle Modification in the Management of Hypertension among Hypertensives in South-East Nigeria. International Journal of Medicine and Biomedical Research, 3, 121-131. https://doi.org/10.14194/ijmbr.3.2.8

[16] Shrestha, S. (2016) Barriers and Facilitators to Treatment among Newly Diagnosed Hypertensive Patients in Nepal: A Qualitative Study.

[17] Lutfey, K.E. and Wishner, W.J. (1999) Beyond Compliance Is Adherence. Improving the Prospect of Diabetes Care. Diabetes Care, 22, 635-639. https://doi.org/10.2337/diacare.22.4.635

[18] Trief, P.M., Ploutz-Snyder, R., Britton, K.D. and Weinstock, R.S. (2004) The Relationship between Marital Quality and Adherence to the Diabetes Care Regimen. Annals of Behavioral Medicine, 27, 148-154.

https://doi.org/10.1207/s15324796abm2703_2

[19] Parajuli, J., Saleh, F., Thapa, N. and Ali, L. (2014) Factors Associated with Non-Adherence to Diet and Physical Activity among Nepalese Type 2 Diabetes Patients: A Cross Sectional Study. BMC Research Notes, 7, 758. https://doi.org/10.1186/1756-0500-7-758

[20] Thomas, N., Alder, E. and Leese, G. (2004) Barriers to Physical Activity in Patients with Diabetes. Postgraduate Medical Journal, 80, 287-291. https://doi.org/10.1136/pgmj.2003.010553

[21] Yosefy, C., Jafari, J., Klainman, E., Brodkin, B., Handschumacher, M.D. and Vaturi, M. (2006) The Prognostic Value of Post-Exercise Blood Pressure Reduction in Patients with Hypertensive Response during Exercise Stress Test. International Journal of Cardiology, 111, 352-357. https://doi.org/10.1016/j.ijcard.2005.07.039

[22] Grove, C. and Laennec, N. (2005) Harrison's Principles of Internal Medicine.

[23] Owusu, I. (2007) Causes of Heart Failure as Seen in Kumasi, Ghana. Internet Journal of Third World Medicine, 5, 1538-4646.

[24] Plange-Rhule, J., Phillips, R., Acheampong, J., Saggar-Malik, A., Cappuccio, F. and Eastwood, J. (1999) Hypertension and Renal Failure in Kumasi, Ghana. Journal of Human Hypertension, 13, 37-40. https://doi.org/10.1038/sj.jhh.1000726

[25] Wiredu, E. and Nyame, P. (2001) Stroke-Related Mortality at Korle Bu Teaching Hospital, Accra, Ghana. East African Medical Journal, 78, 180-184. https://doi.org/10.4314/eamj.v78i4.9059

[26] Asmar, R. (2003) Benefits of Blood Pressure Reduction in Elderly Patients. Journal of Hypertension, 21, 25-30. https://doi.org/10.1097/00004872-200307006-00005 